\title{
RELAÇÃO SOLO-PAISAGEM E SUA APLICABILIDADE: Uma ferramenta fundamental para o entendimento da caracterização da paisagem
}

Brunno Cesar Pereira ${ }^{1}$

\begin{abstract}
Resumo: Este trabalho tem como objetivo apresentar as diversas aplicabilidades da relação solo-paisagem, como é trabalhada e quais análises dos solos são fundamentais para a construção do entendimento em busca de respostas acerca de questões norteadoras levantadas pelo pesquisador, dentre outras. Para isso, foi realizado um breve levantamento literário, coletando artigos e trabalhos de pesquisa que apresentam como temática a relação solo-paisagem, identificando como foi utilizada para discutir as questões norteadoras, bem como refutar ou corroborar com as hipóteses levantadas, com o intuito de alcançar os objetivos propostos. Com o levantamento bibliográfico, que apresenta como temática esta relação mútua, será possível identificar as variedades de uso e aplicação, observando os objetivos de cada pesquisa e como foram alcançados através do uso da relação solo-paisagem. Muitos estudos buscam através da relação entre os solos e a paisagem respostas acerca das características do local em que estão inseridos, disposição e composição da vegetação, propriedades em comum a outras áreas semelhantes, além do grau evolutivo de superfícies e suas características. Nota-se que o uso da relação mútua entre os solos e a paisagem foi fundamental em várias análises, como caracterização, descrição e evolução da paisagem, uso sustentável das terras, dentre outros.
\end{abstract}

Palavras-chave: Solos, Paisagem, Relevo, Mutualidade.

SOIL-L ANDSCAPE RELATIONSHIP AND ITS APPLICABILITY: A fundamental tool for understanding the characterization of the landscape

Abstract: This work aims to present the various applicability of the soil-landscape relationship, how it is worked and which soil analyzes are fundamental for the construction of understanding in search of answers about guiding questions raised by the researcher, among others. For this, a brief literary survey was carried out, collecting articles and research papers that present the soil-landscape relationship as the theme, identifying how it was used to discuss the guiding questions, as well as to refute or corroborate the hypotheses raised, in order to achieve the proposed objectives. With the bibliographic survey, which presents this mutual relationship as the theme, it will be possible to identify the varieties of use and application, observing the objectives of each research and how they were achieved through the use of the soil-landscape relationship. Many studies seek through the relationship between soils and the landscape answers about the characteristics of the place in which they are inserted, layout and composition of vegetation, properties in common with other similar areas, in addition to the evolutionary degree of surfaces and their characteristics. It is noted that the use of the mutual relationship between soils and the landscape was fundamental in several analyzes, such as characterization, description and evolution of the landscape, sustainable use of land, among others.

Keywords: Soils, Landscape, Relief, Mutuality.

\footnotetext{
${ }^{1}$ Universidade Federal de Minas Gerais - IGC - brbuc@ hotmail.com
} 


\section{1 - INTRODUÇÃO E OBJETIVOS}

Os solos e seus atributos são componentes da paisagem, evoluindo concomitantemente, apresentando registros dessa última ao longo do tempo em suas características. Para entender a relação solo-paisagem e a sua aplicação é necessário compreender os dois termos em questão separadamente, para buscar o caminho entre eles e as formas como são analisados em conjunto.

As características dos solos e seus atributos são ferramentas importantes para estudos que buscam relacionar os mesmos com a superfície em que estão inseridos. Considerado como corpo tridimensional e dinâmico, a sua variação ao longo do tempo é acompanhada pelas mudanças na paisagem, apontando a relação mútua entre eles. Por tanto, os solos estão sujeitos a mudanças decorrentes das condições estabelecidas pelo local em que estão inseridos. Destas mudanças pode-se destacar as alterações no relevo; alternância hídrica superficial e de subsuperfície; e também não descartando as alterações impostas pela ação antrópica, muito atuante em regiões em que o solo é o componente fundamental para o desenvolvimento econômico, social, político e cultural.

Segundo Lepsch et al. (1991), os solos, ocupando a porção superior da crosta terrestre, podem ser considerados como o conjunto de corpos tridimensionais capazes de sustentar vegetação, com atributos internos próprios, fazendo com o que se diferenciem. Além das características internas, os solos possuem os atributos externos, tais como declividade, pedregosidade, rochosidade, de modo que é possível descrevê-los e classificálos. Os solos possuem propriedade que permitem definir os processos e mecanismos responsáveis pela sua formação e evolução, tendo as características morfológicas, morfometria do solo e a caracterização dos agentes causais como as principais (QUEIROZ NETO, 1984). Essas análises auxiliam nos estudos de superfície com a paisagem em conjunto, tendo o solo como componente fundamental.

A paisagem apresenta uma complexidade entorno da sua definição, mas de modo geral é definida como a combinação entre as feições da superfície terrestre, com destaque para o relevo, e os componentes de subsuperfície, como os solos, a atividade hídrica etc. Sobre a relação homem e natureza como agentes de definição da paisagem, Santos (1997) destaca que a paisagem é o resultado da herança de sucessivas relações entre os dois componentes, sendo sua existência fundamentada no conjunto de formas e objetos concretos.

Por ser uma porção do espaço em constante modificação, a paisagem é o resultado da combinação dinâmica de elementos físicos, biológicos e antrópicos que, ao reagirem, 
fazem da paisagem um conjunto único e intrínseco, em constante evolução (BERTRAND, 1972).

A relação solo-paisagem é um instrumento interessante quando o objetivo é caracterizar a paisagem e como ela se comporta no presente, além de levantar registros do passado e realizar prospecção futura. Muitos estudos utilizam dessa relação mútua para entender a evolução da superfície, o comportamento do relevo e do espaço que está inserido, funcionamento hídrico de percolação e escoamento superficial e de subsuperfície, dentre outras funções que serão descritas nesse trabalho.

Há uma discussão de que os estudos da relação solo-paisagem se iniciaram com o próprio surgimento da definição de solo, aqui em destaque o russo Vaseli V. Dockuchaev, no final do século XIX. Essa discussão baseia-se no simples fato de que o relevo é um fator de formação, entretanto os registros de estudos dessa natureza somente começam surgir mais tarde. Milne (1935) é um dos precursores, relacionando o desenvolvimento do perfil e comportamento dos atributos do solo com as características do relevo, estudo esse realizado no oeste da África. Mais tarde, Milne (1936) sugere o conceito de catena, afirmando que as mudanças na paisagem interferem diretamente na distribuição e comportamento dos solos (CAMPOS, 2012).

Os estudos da relação solo-paisagem no Brasil iniciaram-se na década de 1960. Porém ganhou mais força na década de 1970, com estudos de Klamt \& Beatty (1972), com análise de desenvolvimentos dos solos em diferentes posições na paisagem; Lepsch et al. (1977), citados por Campos (2012), destacando que a variabilidade dos solos e seus atributos são provenientes de pequenas variações do relevo; e Rodrigues \& Klamt (1978), que encontraram relações do comportamento das propriedades do solo com a disposição do relevo.

Para tanto, este trabalho tem como objetivo apresentar as diversas aplicabilidades da relação solo-paisagem, além de apresentar como é trabalhada e quais análises dos solos são fundamentais para a construção do entendimento em busca de respostas acerca de questões norteadoras levantadas pelo pesquisador, dentre outras. Para essa análise, um breve levantamento bibliográfico foi realizado com a coleta de trabalhos de pesquisa, divididos em temáticas por subitens, com o intuito de apresentar as diversas formas de como a relação solo-paisagem foi empregada, de maneira a compreender os problemas levantados pelos autores. Além disso, entender como o uso da relação solo-paisagem pode contribuir para a construção crítica sobre as problemáticas apresentadas pelos autores, com finalidade de cumprir os objetivos propostos, além de refutar ou corroborar com as hipóteses levantadas a partir dos possíveis questionamentos da pesquisa. 


\section{2 - RELAÇÃO SOLO-PAISAGEM PARA O ENTENDIMENTO DA CARACTERIZAÇÃO DA PAISAGEM}

Os estudos acerca da paisagem e sua caracterização utilizam-se de várias ferramentas, tendo com destaque a relação mútua entre os solos e a paisagem. Ao analisar a paisagem é fundamental observar os seus constituintes, esses incluindo os solos, que sustentam os elementos de superfície, como a vegetação, além dos de subsuperfície. Por serem elementos da paisagem, uma pequena mudança na superfície interfere na dinâmica superficial e subsuperficial dos solos, ocasionando modificações estruturais, sendo refletidas na própria paisagem.

Iniciando as discussões, Campos et al. (2007) utilizaram das relações solo-paisagem com o objetivo de relacionar os solos com as superfícies geomórficas em uma litossequência de transição arenito-basalto. Os autores tinham como intuito identificar áreas específicas mais homogêneas, auxiliando levantamentos pedológicos. Foi possível identificar a correlação entre os solos e as superfícies, principalmente utilizando um dado importante dos solos para relatar a idade relativa das superfícies, a relação silte/argila. Essa relação é bastante utilizada para estudos sobre evolução de superfícies, tendo como premissa de que quanto maior o valor mais rejuvenescido é o solo, pois a quantidade do conteúdo de argila é inferior comparado ao solo mais evoluído. Por fim, os autores confirmaram que as características do solo apresentaram limites próximos aos das superfícies geomórficas.

A correlação entre os solos e a paisagem pode ser explicada pelo o entendimento dos componentes dessa última, sendo os solos um importante elemento, que evoluem concomitantemente com a paisagem. Estando inseridos na paisagem, os solos apresentam proximidade em se tratando de suas características, destacando a sua importante participação nas análises sobre a paisagem.

A paisagem pode dizer muito sobre o comportamento dos solos nela inseridos. Dantas et al. (2014) explicitam que a posição da paisagem foi determinante para a diferenciação dos solos, sendo os de maior expressão do caráter coeso em pedoforma côncava, apresentando maior índice de fertilidade e matéria orgânica, por conta da condição de acúmulo de nutrientes pela forma do relevo e, consequentemente, vegetação mais exuberante. Os solos, como estudado por Dantas et al. (2014), podem determinar o tipo de vegetação encontrada na paisagem, ou mesmo o tipo de atividade mais favorável, através de acúmulo orgânico, condições estruturais para percolação hídrico, estabilidade e atividades biológicas. 
As formas do relevo determinam o desenvolvimento dos solos inseridos na paisagem, o que implica diretamente na caracterização dessa última. Áreas em que o relevo apresenta formas côncavas possibilita maior acúmulo de matéria orgânica, pois a perda desse material é menor, aumentando a fertilidade nesse ambiente. Com o acréscimo de nutrientes pelo acúmulo orgânico, a vegetação acompanha essa grande quantidade de matéria orgânica, permitindo distinguir essas áreas de outras em que o relevo propicia diferentes características e condicionantes para o desenvolvimento pedológico. Essa mesma observação pode ser aplicada em áreas planas, em que o relevo condiciona um desenvolvimento maior dos solos, ou em locais alagados a partir do relevo plano, sendo o ambiente caracterizado pelos solos hidromórficos. Nesses casos, a relação solo-paisagem é fundamental para compreender e levantar informações sobre a paisagem.

Entender o relevo, também componente da paisagem, e suas formas é importante para analisar as características dos solos e seus atributos, o que por sua vez refletem na composição da paisagem. Rossi \& Queiroz Neto (2001), que estudaram a relação solopaisagem na região da Serra do Mar em São Paulo, concluíram que as paisagens atuais da região fazem parte de uma intrínseca rede de trocas, com o relevo condicionando diretamente no comportamento hídrico de superfície e subsuperfície. A percolação hídrica interfere no processo de formação do solo, sendo responsável pela evolução das formas do relevo, através da alteração dos solos.

Existem estudos que buscam da relação solo-paisagem a compreensão sobre a evolução de superfícies, partindo do pressuposto que os solos são constituintes da própria paisagem. Sendo assim, os solos apresentam uma correlação com a paisagem, evoluindo concomitantemente.

Em se tratando de evolução da paisagem, Daniels et al. (1971) consideraram a idade dos solos como sendo correlata com a mesma da respectiva superfície geomórfica em que estão inseridos. Ainda, segundo Cunha et al. (2005), os solos na superfície geomórfica localizada na parte mais elevada e menos inclinada da área de estudo são os mais velhos, decrescendo na medida em que analisam outras superfícies menos elevadas. Constataram ainda que a idade do solo corresponde com a das superfícies, confirmando a suas aproximações.

Simões (2016) também utiliza da relação solo-paisagem para abordar a geomorfogênese do seu local de estudo, identificando a correlação entre os solos e a paisagem. A autora investigou a geomorfogênese de trecho da borda oeste do Planalto do Espinhaço Meridional, em Minas Gerais. Os estudos tiveram como foco principal extrapolar 
as informações para investigar o comportamento das quatro superfícies estudadas. Os resultados das análises de solo confirmaram a hipótese de que as superfícies de menor altimetria apresentam um menor grau de intemperismo, o que indica um menor grau de desenvolvimento dos solos, principalmente comparando-se aos da superfície mais elevada. A mesma observação foi relatada por Pereira (2019), que estudou duas superfícies geomórficas na região da Zona da Mata mineira, com o intuito de levantar a cronologia relativa delas. O autor constatou que os solos da superfície superior são mais evoluídos comparados aos da superfície inferior, sendo essa última menos evoluída.

Ainda sobre evolução de superfícies e da paisagem, Meireles et al. (2012), que tiveram como enfoque as relações solo-paisagem em topossequência de origem balsáltica na região de Batatais (SP), observaram que os teores da fração de argila dos solos estudados diminuíram com o aumento do grau de rejuvenescimento das superfícies geomórficas. Dessa forma, quanto mais evoluído é o solo, maior é seu teor de argila, pois com o intemperismo a tendência é a redução do tamanho dos grãos que constituem o material de solo, acarretando em um aumento da quantidade de argila.

Para tanto, compreende-se que a relação mútua entre os solos e a paisagem permite auxiliar na caracterização dessa última, determinando as feições que se comportam de acordo com o tipo de solo e seus atributos presentes e, por consequência, os grupos vegetacionais, que por sua vez interfere na dinâmica ecológica e na aplicação de atividades antrópicas.

\section{3 - A RELAÇÃO SOLO-PAISAGEM COMO SUBSÍDIO AOS ESTUDOS DE SUSTENTABILIDADE E AO PLANEJAMENTO DE USO DA TERRA}

Outra aplicabilidade da relação solo-paisagem se concentra nos estudos de preservação ambiental, conhecimento de áreas protegidas, levantamento de uso sustentável e planejamento de uso da terra. O conhecimento dos solos presentes na paisagem permite identificar as melhores formas de uso dessas áreas, além de definir parâmetros que visam a sustentabilidade, principalmente de áreas preservadas.

Iniciando as discussões, a respeito de estudos que visam o uso sustentável, Lumbreras (2008) caracterizou as relações solo-paisagem, com a finalidade em avaliar a qualidade do solo. Além disso, levantar as potencialidades e limitações das terras na região noroeste do Rio de Janeiro, contribuindo, assim, para o planejamento de seu uso sustentável. O autor concluiu que o conhecimento da qualidade do solo e das interrelações dos fatores pedoambientais efetivamente pode contribuir para a melhoria ou reformulação de 
alternativas de uso sustentável das terras, o que contribuiria para a redução de áreas degradadas pelo uso inadequado.

Quanto ao uso da relação solo-paisagem como subsídio para sustentabilidade ambiental, Calderano Filho (2012) analisou geoambientes de paisagens rurais montanhosas da Serra do Mar, visando a sustentabilidade de ecossistemas frágeis, que estão sob interferência antrópica. Buscando criar um modelo econômico-ambiental de intervenção no meio que permita o uso produtivo sustentável de recursos naturais, o autor utilizou de diagnóstico geoambiental, aspectos socioeconômicos e aplicação de Redes Neurais Artificias, com o uso de Sistema de Informação Geográfica, para realizar uma predição de classes de solos de paisagens rurais montanhosas da Serra do Mar. Essas classes auxiliariam na compreensão das unidades geoambientais, levantando as suas potencialidades, limitações e fragilidades, sugerindo formas de usos alternativos em função, segundo o autor, das vocações agroecológicas apresentadas em cada unidade delimitada.

Ainda sobre ambientes serranos, Mendes (2020) se apropria da relação solo-paisagem para associá-la com as áreas de potencialidade e susceptibilidade ambiental na serra da Meruoca, com intuito de entender a relação entre o solo e a paisagem com os elementos naturais e sociais envolvidos nessa relação. Nesta pesquisa, a relação mútua entre os solos e a paisagem permitiu identificar classes de solos, como os Argissolos Vermelho-Amarelos, que possuem um bom desempenho agrícola, devendo serem conservados e manejados com práticas sustentáveis, já que o seu principal uso é para a cultura de subsistência, que contribui para manutenção da potencialidade da área de estudo. Além disso, a pesquisa permitiu propor algumas práticas conservacionistas para áreas que se encontram em processo de degradação, que apresentam vulnerabilidade quanto ao desequilíbrio ambiental.

Os estudos da relação solo-paisagem para o auxílio do uso sustentável da terra e da avaliação ambiental foram fundamentais para tais objetivos propostos. Para avaliar o uso de maneira sustentável, visando melhor aproveitamento das terras, de modo preservar suas características naturais, as análises dos solos e seus atributos se tornam necessárias, principalmente em se tratando os solos como componentes da própria paisagem, que trazem informações importantes dessa última, tanto no passado e presente quanto uma prospecção de uso local.

Quanto ao planejamento de uso da terra existem alguns métodos de análise para realizar tal interpretação e caracterização, visando melhor aproveitamento do solo, dentre eles a aplicação da relação mútua entre os solos e a paisagem. Calegari \& Marcolin (2014) citam que os estudos da relação entre solo e relevo, consequentemente da paisagem, entre 
seus fatores e processos de formação, são importantes para a compreensão da organização e distribuição dos solos na paisagem. Desta forma, constituem importante ferramenta para mapeamentos e planejamento do uso da terra, além do entendimento da dinâmica dos processos socioambientais. Os autores estudaram as correlações e interações entre os solos e o relevo no Oeste do Paraná, concluindo que a distribuição dos solos na vertente estudada revela uma estreita relação entre a morfologia do relevo e a organização e distribuição dos solos na paisagem.

Existem estudos que avaliam o uso da terra em diferentes temporalidades, para buscar entender as características da paisagem a partir dos variados usos no decorrer do tempo. Soares et al. (2015) buscaram caracterizar os componentes da paisagem e de suas relações numa estação experimental de silvicultura em Santa Maria-RS, além de monitorar a variação temporal solo-paisagem em 22 anos (1987 a 2009). No período mencionado, os autores concluíram que houve um caráter transitório dos componentes da paisagem, com uma redução das características naturais, expansão da silvicultura e, em alguns locais, expansão da floresta nativa. Além disso, ocorreram conflitos de uso do solo pela implementação de cultivos florestais aptas para preservação permanente e concluíram que o relevo e a gênese dos solos foram condicionantes para o desenvolvimento fitofisionômico.

Por estarem inseridos na paisagem, os solos e seus atributos físicos e químicos são influenciados pelo uso agrícola e posição na paisagem, sendo assim sensíveis em diferentes ambientes. Pensando nisso, Cavalcante (2016) buscou detectar quais atributos de um solo, físicos e químicos, foram os mais sensíveis na distinção dos ambientes, além da sua classificação em relação a paisagem e usos agrícolas. A autora constatou que ambientes agrícolas com alta reposição de material orgânico no solo, como o capim elefante, favoreceu a maior agregação e estabilidade de agregados no solo, sendo um ambiente favorável para manutenção da sustentabilidade agrícola. Além disso, as análises químicas dos solos foram fundamentais como indicadores da separação dos ambientes, pois o local determina a quantidade de elementos químicos, tanto pela posição na paisagem quanto pelas características estruturais dos solos.

Para planejamento de uso da terra percebe-se a necessidade do conhecimento dos solos presentes na paisagem, identificando as suas potencialidades e fragilidades, sem subestimar ou superestimar as suas características, com a finalidade de melhor aproveitamento do uso da terra. Uma das ferramentas mais utilizadas, se não a mais importante, é a relação solo-paisagem, que permite associar os solos com o contexto da 
paisagem e auxilia na predição das melhores formas de uso, até mesmo auxiliar nas atividades a serem desenvolvidas no espaço.

A relação solo-paisagem, observando os trabalhos coletados nesse subitem, foram fundamentais para levantar informações importantes e necessárias para o desenvolvimento local de maneira sustentável, preservando ambientes naturais, ou mesmo para adequação e melhor uso da terra, preservando as necessidades socioeconômicas. É importante salientar que para melhor apreciação da paisagem, com os estudos dos solos e seus atributos, se faz necessário o uso correto de métodos de análise, correlacionando-os entre si e com as características da paisagem e dos solos nela inseridos.

\section{4 - ALGUNS PROCEDIMENTOS METODOLÓGICOS NAS ANÁLISES DE SOLOS PARA A DESCRIÇÃO DA PAISAGEM}

Existem alguns procedimentos metodológicos que auxiliam na análise do solo e, consequentemente, na caracterização da paisagem, seja para determinar a sua evolução por cronologia relativa, suas propriedades, seu desenvolvimento no passado e presente, além de permitir determinar uma prospecção a partir dessas análises. Esses procedimentos não necessariamente são analisados separadamente, mas sim realizando estudos comparativos entre ambos para construir uma análise descritiva e crítica sobre o objeto de estudo.

Com o auxílio da descrição e análise pedológica, principalmente a partir de análises laboratoriais, informações como análise textural, relação silte/argila, $\Delta \mathrm{pH}$, mineralogia, micromorfologia, condutividade elétrica no solo, dentre outros, permitem extrapolar para a escala da paisagem a partir de estudos do solo.

Pereira (2019) analisou duas superfícies morfológicas de altimetrias diferentes na Zona da Mata mineira com o intuito em realizar a cronologia relativa entre elas, tendo como auxílio a análise de Latossolos. $O$ autor utilizou para realizar essa distinção a relação silte/argila, textura, $\Delta \mathrm{pH}$, condutividade elétrica, ataque sulfúrico, mineralogia e micromorfologia, sendo ambas representativas para a realização da pesquisa. Maiores teores da relação silte/argila foram relacionadas com a superfície menos evoluída, onde se encontra solos menos evoluídos em comparação aos da superfície mais elevada. Consequentemente, a textura para os solos da superfície superior é muito argilosa, diferente dos solos menos evoluídos, que apresentaram textura argilosa. A micromorfologia permitiu auxiliar na quantificação textural, sendo os solos mais evoluídos apresentando maior distribuição relativa de material fino (argila), coincidindo com o maior teor de argila. As metodologias 
mencionadas foram fundamentais para a execução da pesquisa, contribuindo para o alcance dos objetivos e respostas quanto às hipóteses.

Assim como Pereira (2019), Cunha et al. (2005); Campos et al. (2007); e Meireles et al. (2012) também analisaram a fração argila dos solos das suas respectivas áreas de estudo. Ambos constataram que os conteúdos de argila foram crescentes dos solos das superfícies mais rejuvenescidas para os da superfície mais evoluída, o que corrobora com a correlação entre os solos e a paisagem. É possível observar que a análise textural dos solos é uma ferramenta importante para levantar as características evolutivas dos solos e, consequentemente, das superfícies em que os mesmos estão inseridos.

Machini (2012), que estudou a relação solo-paisagem em um transecto na região do Rio Claro-SP, aplicou algumas metodologias de análise dos solos para a compreensão de suas relações genéticas e cronológicas na evolução das paisagens da área. Dentre as análises executadas, destacam-se o coeficiente de intemperismo e difratometria de raios-X para análises mineralógicas. Com as análises, permitiu verificar o grau de intemperismo dos solos estudados e fertilidade, o que implica no manejo desses solos e o uso da terra dessas paisagens.

Para o estudo das correlações e interações entre os solos e o relevo, Calegari \& Marcolin (2014) buscaram, dentre outras análises, caracterizar morfologicamente os solos da área de estudo, sendo comparados com a sua posição na paisagem. As características dos solos encontrados correspondem à morfologia do relevo, em que solos mais aprofundados são correlacionados ao relevo mais aplainado, ou solos menos profundos em relevo acidentado. As análises físicas foram bastante interessantes, em que a densidade do solo apresentou resultados consideráveis, onde solos com menor porosidade devido ao uso de maquinário, ocasionando compactação dos horizontes superficiais, são mais susceptíveis à erosão. A observação em campo, em conjunto com a identificação da natureza dos solos a partir das análises físicas e químicas, constataram que a distribuição dos solos na paisagem varia conforme às alterações do relevo, concordando com o contexto regional. Os autores concluíram que o controle da distribuição pedológica está condicionado principalmente à evolução morfogenética da região, como, por exemplo, solos localizados nos topos amplos e alongados, locais mais estáveis, também apresentam estabilidade e são mais aprofundados.

As análises químicas e de ataque sulfúrico também apresentam grande contribuição para os estudos dos solos e sua correlação com a paisagem. Demattê et al. (1994), analisando uma sequência pedológica da região amazônica, constataram, com o auxílio do ataque sulfúrico e o levantamento dos óxidos presentes nos solos, um maior teor de óxidos de 
alumínio e ferro para os solos mais evoluídos, o que também foi relatado por Campos et al. (2011), que estudaram a relação solo-paisagem em uma topossequência em Manicoré-AM, verificando teores mais expressivos nas áreas de topo, quando comparados às áreas de encosta e sopé de transporte da topossequência pesquisada. $\mathrm{O} \Delta \mathrm{pH}$, presente nas análises químicas dos solos, exibem resultados que auxiliam na investigação sobre a evolução dos solos, consequentemente da paisagem. Campos et al. (2012) associaram os maiores valores de $\Delta \mathrm{pH}$ negativos às superfícies geomórficas menos evoluídas, mesma observação relatada por Meireles et al. (2012) e Pereira (2019).

Soares et al. (2015), com o auxílio das análises físicas e morfológicas dos solos, observaram registros de conflitos de uso do solo, pela implantação de cultivos florestais em terras sob Gleissolo Háplico e Neossolo Litólico, aptas para preservação permanente. Outra contribuição com as características físicas dos solos se dá no avanço do cultivo de Eucalyptus e Pinus em solos mais argilosos.

Para avaliação da qualidade do solo, Lumbreras (2008) utilizou indicadores da qualidade física e química, mostrando adequação e complementação. Pode-se destacar como exemplos de indicadores o levantamento dos elementos químicos (mineralogia do solo), susceptibilidade à erosão, fertilidade do solo, porosidade, dentre outros não menos importantes. As análises físicas permitiram identificar como o uso do solo pode contribuir para avaliação de degradação ou preservação. A exemplo, áreas utilizadas com pastagens, em que os Latossolos e Argissolos estão presentes, sofreram degradação física no horizonte superficial, relacionada com o pisoteio da criação. Em áreas mais rebaixadas apresentaram limitações relacionadas à drenagem deficiente, principalmente com a constatação de que os solos exibem redução de aeração pela análise de porosidade, o que dificulta a permeabilidade, além de terem argilas expansivas, que ao encharcarem reduzem ainda mais o espaço poroso através de seu caráter expansivo.

Por tanto, as análises dos solos auxiliaram para corroborar com a correlação existente entre os solos e a paisagem, vistos nos estudos levantados nesse artigo, e como essa aproximação e mutualidade possibilita realizar estudos sobre o uso correto da terra, correção dos solos para aplicação agrícola quando há necessidade, prospecção de ocorrências a partir da susceptibilidade quanto aos processos erosivos, o que modifica a paisagem, além de levantamentos para estudos sobre preservação ambiental e proteção de áreas naturais. 


\section{5 - CONSIDERAÇÕES FINAIS}

Sendo componentes da paisagem, os solos são ferramentas fundamentais para análise do comportamento, caracterização e evolução da paisagem, o que implica no maior uso de seus atributos. Com isso, a relação solo-paisagem se torna importante para estudos que visam analisar a paisagem tendo como base um dos seus principais componentes.

Tendo como subsídio da relação solo-paisagem, os estudos levantados nesta pesquisa alcançaram os objetivos propostos de maneira eficiente, o que nos mostra a importância do uso desta relação mútua entre os solos e a paisagem. A participação dos solos e seus atributos nos estudos da paisagem foi fundamental para investigar características próprias presentes nas áreas de estudo de cada pesquisa.

Pode-se destacar os solos como componentes que guardam registros da paisagem ao longo do tempo, auxiliando nos estudos investigativos do passado, atuação e execução de atividades no presente e em levantamentos prospectivos. Como evoluem concomitantemente com a paisagem, os solos carregam informações dessa última, sendo analisadas a partir dos estudos morfológicos, físicos, químicos, mineralógicos, micromorfológicos, dentre outros, contrapondo com a ideia da relação solo-paisagem.

As análises de solos realizadas nas pesquisas abordadas foram fundamentais para alavancar informações importantes sobre as superfícies estudadas, conciliando com as características da paisagem e como essa última pode interferir diretamente na formação do solo e em seu desenvolvimento ao longo do tempo. Portanto, uma mudança na paisagem condiciona em alterações pedológicas, que interferem na composição da vegetação e da vida sobre essa paisagem.

Por fim, observa-se que a relação solo-paisagem foi um instrumento muito importante para as pesquisas citadas, permitindo avaliar as características da paisagem contrapondo com os solos e seus atributos.

\section{REFERÊNCIAS BIBLIOGRÁFICAS}

BERTRAND, G. Paisagem e Geografia Física Global. Esboço Metodológico. Caderno de Ciências da Terra, Instituto de Geografia da Universidade Federal de São Paulo, n. 13, 1972. Traduzido por: Olga Cruz, publicado em: R. RA’E GA, Editora UFPR. Curitiba, n. 8, 2004. p. $141-152$.

CALDERANO FILHO, B. Análise geoambiental de paisagens rurais montanhosas da Serra do Mar utilizando redes neurais artificiais. Subsídios a sustentabilidade ambiental de ecossistemas frágeis 
e fragmentados sob interferência antrópica. Tese apresentada ao Programa de PósGraduação em Geologia da UFRJ, 2012. 322 p. Rio de Janeiro-RJ.

CALEGARI, M. R. \& MARCOLIN L. Relação solo-paisagem na bacia da Sanga Matilde Cuê, Marechal Cândido Rodon (PR). Bol. Geogr., Maringá, v. 32, n. 3, 2014. p. 110-121.

CAMPOS, M. C. C.; MARQUES JÚNIOR, J.; PEREIRA, G.T.; MONTANARI, R. \& CAMARGO, L. A. Relações solo-paisagem em uma litossequência arenito-basalto na região de Pereira Barreto, SP. R. Bras. Ci. Solo, edição 31, 2007. p. 519-529.

CAMPOS, M. C. C.; RIBEIRO, M. R.; SOUZA JÚNIOR, S.; RIBEIRO FILHO, M. R. \& SOUZA, R. V. C. C. Relações solo-paisagem em uma topossequência sobre substrato granítico em Santo Antônio do Matupi, Manicoré (AM). Revista Brasileira de Ciência do Solo, edição 35, 2011. p. 13-23.

CAMPOS, M. C. C. Relações solo-paisagem: conceitos, evolução e aplicações. Ambiência Guarapuava (PR) v.8 n.3, 2012. p. 963-982.

CAVALCANTE, J. S. J. Relações solo-paisagem associadas aos usos agricolas no município de Martins - RN. Dissertação apresentada ao Programa de Pós-Graduação em Manejo de Solo e Água, UFERSA, 2016. 75 p. Mossoró-RN.

CUNHA, P.; MARQUES JÚNIOR, J.; CURI, N.; PEREIRA, G. T. \& LEPSCH, I. F. Superfícies geomórficas e atributos de Latossolos em uma sequência arenítico-basáltica da região de Jaboticabal (SP). R. Bras. Ci. Solo, 29, 2005. p. 81-90.

DANIELS, R. B.; GAMBLE, E. E. \& CADY, J. G. The relation between geomorphology and soil morphology and genesis. Adv. Agron., 23, 1971. p. 51-87.

DANTAS, J. S.; MARQUES JÚNIOR, J.; MARTINS FILHO, M. V.; RESENDE, J. M. A.; CAMARGO, L. A. \& BARBOSA, R. S. Gênese de solos coesos do leste maranhense: relação solo-paisagem. R. Bras. Ci. Solo, 38, 2014. p. 1039-1050.

DEMATTÊ, J. A. M.; ALOISI, R. R. \& DEMATTÊ, J. L. I. Sequência Latossolo Amarelo - Podzólico Amarelo - Areias Quartzosas sob material da Formação Barreiras na região de Tucuruí, Estado do Pará. Scientia Agricola, v.51, n.2, 1994. p.345-356.

KLAMT, N.; BEATTY, M. T. Gênese duma sequência de solos da região do Planalto médio Riograndense. Pesquisa Agropecuária Brasileira, Brasília, v.7, 1972. p.99-109.

LEPSCH, I. F.; BELLINAZZI JÚNIOR, R.; BERTOLINI, D. \& ESPINDOLA, C. R. Manual para levantamento utilitário do meio físico e classificaşão de terras no sistema de capacidade de uso. 2. ed. Campinas: Sociedade Brasileira de Ciência do Solo, 1991. 170 p.

LUMBRERAS, J. F. Relações solo-paisagem no noroeste do estado do Rio de Janeiro: subsídios ao planejamento de uso sustentável em áreas de relevo acidentado do bioma Mata Atlântica. Tese apresentada ao Programa de Pós-Graduação em Geografia da UFRJ, 2008. 306 p. Rio de Janeiro-RJ.

MACHINI, P. L. F. Relação solo-paisagem em um transecto da depressão periférica e do planalto ocidental, região de Rio Claro (SP). Trabalho de conclusão de curso apresentado ao Instituto de Biociências da Universidade Estadual Paulista, 2012. 81 p. Rio Claro-SP.

MENDES, M. V. R. Relação solo/paisagem da serra da Meruoca/Ceará: potencialidade e susceptibilidade ambiental. Dissertação apresentada ao Departamento de Geografia da Universidade Estadual Vale do Acaraú (UVA), 2020. 108 p. Sobral-CE. 
MEIRELES, H. T.; MARQUES JÚNIOR, J.; CAMPOS, M. C. C. \& PEREIRA, G. T. Relações solo-paisagem em topossequência de origem basáltica. Pesq. Agropec. Trop., Goiânia, v. 42, n. 2, 2012. p. 129-136.

PEREIRA, B. C. Caracterização de Latossolos de Mares de Morros Florestados- MG como subsídio para o entendimento da evolução dos compartimentos geomorfológicos. Dissertação apresentada ao Programa de Pós-Graduação em Geografia, UFMG, 2019. 110 p. Belo Horizonte-MG.

QUEIROZ NETO, J. P. Pedologia: Conceito, Método e Aplicações. RDG - Revista do Departamento de Geografia, USP, v. 3, 1984. p. 95-102. Disponível em: <revistas.usp.br/rdg/article/download/47088/50809>. Acesso em 12 de jan. de 2021.

RODRIGUES, T. E.; KLAMT, E. Mineralogia e gênese de uma sequência de solos do Distrito Federal. Revista Brasileira de Ciência do Solo, Campinas, v.2, 1978. p.132-139.

ROSSI, M. \& QUEIROZ NETO, J. P. Relações Solo/Paisagem em regiões tropicais úmidas: o exemplo da Serra do Mar em São Paulo, Brasil. Revista do Departamento de Geografia, 14, 2001. p. 11-23.

SANTOS, M. A Natureza do Espaço. Técnica e Tempo. Razão e Emoção. $2^{\circ}$ Edição. São Paulo: Hucitec, 1997. 258 p.

SIMÕES, P. M. L. Geomorfogênese de trecho da borda oeste do Planalto do Espinhaço Meridional/MG: uma contribuição baseada no possiviel diálogo entre os atributos pedológicos de formações superficiais e a organização geomorfológica regional. Tese do Departamento de Geografia do Instituto de Geociências da Universidade Federal de Minas Gerais, 2010. 152 p. Belo Horizonte-MG.

SOARES, J. C. W.; REINERT, D. J.; REICHERT, J. M.; KAISER, D. R.; MINELLA, J. P. G.; GONÇALVES, A. D. M. A.; SILVA, T. A.; NETTO, T. A. \& BRESSAN, V. C. Relação solo/paisagem e sua variação temporal em uma estação experimental de silvicultura. Ciência Florestal, Santa Maria, v. 25, n. 2, 2015. p. 477-489. 